Abstracta Iranica Abstracta Iranica

Revue bibliographique pour le domaine irano-aryen

Volume 30 | 2010

Comptes rendus des publications de 2007

Iran and the Challenge of Diversity. Islamic

Fundamentalism, Aryanist Racism, and Democratic

Struggles. New York, Palgrave Macmillan, 2007, xiv-249 p.

\title{
Gilles Riaux
}

\section{OpenEdition}

\section{Journals}

Édition électronique

URL : http://journals.openedition.org/abstractairanica/38091

DOI : 10.4000/abstractairanica.38091

ISSN : 1961-960X

Éditeur :

CNRS (UMR 7528 Mondes iraniens et indiens), Éditions de l'IFRI

Édition imprimée

Date de publication : 8 avril 2010

ISSN : 0240-8910

Référence électronique

Gilles Riaux, «Iran and the Challenge of Diversity. Islamic Fundamentalism, Aryanist Racism, and

Democratic Struggles. New York, Palgrave Macmillan, 2007, xiv-249 p. », Abstracta Iranica [En ligne],

Volume 30 | 2010, document 297, mis en ligne le 08 avril 2010, consulté le 26 septembre 2020. URL

http://journals.openedition.org/abstractairanica/38091; DOI : https://doi.org/10.4000/

abstractairanica.38091

Ce document a été généré automatiquement le 26 septembre 2020.

Tous droits réservés 


\title{
Iran and the Challenge of Diversity. Islamic Fundamentalism, Aryanist
} Racism, and Democratic Struggles. New York, Palgrave Macmillan, 2007,

\author{
xiv-249 p.
}

\author{
Gilles Riaux
}

1 A partir d'une approche résolument transdisciplinaire qui emprunte à l'histoire, la sociologie, la littérature, la science politique, l'anthropologie, aux cultural studies et aux colonial studies, l'A. entend présenter la genèse et la persistance d'une idéologie raciste en Iran. Celle-ci trouve ses origines dans l'orientalisme européen qui a placé le groupe ethnique persan, de langue indo-européenne, dans une position de supériorité par rapport aux autres groupes ethniques. Il s'est particulièrement bien implanté en Iran $\mathrm{du}$ fait des connections avec les sources persanes anciennes. L'apparition de ce discours dominant introduit une rupture par rapport à la diversité, tant linguistique que religieuse, qui constitue un fondement de l'Iran. Sous le règne de Redā šāh, puis de son fils, cette idéologie a servi de légitimation à la modernisation autoritaire. Derrière ces atours religieux, la Révolution islamique n'a pas entraîné d'inflexion majeure, et le régime républicain aurait largement repris la matrice héritée de la monarchie. La mise en place de cette idéologie et sa promotion par l'Etat a entraîné une "persanisation » $\mathrm{du}$ territoire, des cultures, des langues et de l'éducation, décrite en termes de colonisation. Face à ce discours dominant, s'est développée une résistance sous la forme d'un discours contre-hégémonique et de pratiques d'opposition par des membres des divers groupes ethniques. L'A. présente cette opposition à travers différents exemples, puisés notamment chez les Azerbaïdjanais mais aussi les Arabes, issus de la production littéraire et militante, et de manifestations. Ils sont analysés dans une perspective de démocratisation par la société civile. En dernier lieu, l'A. plaide pour une redéfinition 
de la citoyenneté iranienne qui prenne en compte la diversité du pays et le rôle des politiques publiques en matière d'éducation.

2 La diversité des cadres théoriques auxquels a recours l'A. nuit à l'argumentation générale. Le maniement souvent syncrétique qui en est fait, empêche l'aménagement des conditions d'une controverse bien organisée, et le suivi d'une démarche scientifique rigoureuse. En plus, il est possible de s'interroger sur des biais introduits dans la récolte des données. Le plus frappant est celui de la réduction du nombre des Persans dans la population totale iranienne : le pourcentage donné est un très curieux $35,92 \%$, sans qu'aucune justification ne soit apportée, d'un tel avec les données habituellement rencontrées. Néanmoins, l'ouvrage a le mérite de se pencher sur des champs de recherche délaissées et d'apporter des éléments matériels nouveaux sur l'Iran provincial, tout en resituant les mobilisations actuelles pour la reconnaissance de l'ethnicité dans une perspective historique stimulante.

INDEX

Thèmes : 13.1. Iran

\section{AUTEURS}

GILLES RIAUX

Paris 